\title{
Drama in education: why drama is necessary
}

\author{
Manon van de Water $^{*}$ \\ ${ }^{1}$ University of Wisconsin-Madison, Madison, Wisconsin, USA
}

\begin{abstract}
The article dwells on the use of drama and performance techniques in education and social work in connection with multiple intelligence theory, emotional intelligence theory, and brain based learning. The author connects the use of drama in the alternative theories of teaching and learning based on recent neuroscientific research, and lays out an integrative approach to teaching and learning that promotes inclusion, diversity, and social awareness, through embodied and contextualized learning. If we perceive cognition and emotion as interrelated, then drama as an educational tool becomes essential. It creates metaphors of our lives, which we lead through both cognitive and emotional domains. Art and creativity play an essential role in connections between the body, emotions, and the mind. Moreover, as we live in relationship to the rest of the world around us, our learning is embodied, our brain, emotions, and physiology are constantly connected. Thus, the article demonstrates that drama and performance are vital in teaching the whole child, whether taught as a discipline or used as a teaching tool. This means, the author claims, educators, neuropsychologists, and theatre and drama specialists have to have open minds and be willing to step out of comfort zones and together make a case for using theatre and drama methods as a way to improve human lives.
\end{abstract}

Keywords: performance techniques; multiple intelligence theory; emotional intelligence theory; brain based learning.

\section{Introduction}

In this article, I give an overview of how the use of drama and performance techniques in education and social work connects to multiple intelligence theory, emotional intelligence theory, and brain based learning.

\section{Methods}

Recent neuroscientific research corroborates the notion that drama and performance techniques have the potential to be an effective tool in educating the whole child, whether it is taught as a discipline or an enhancing teaching strategy. I will connect the use of drama in the emerging alternative theories of teaching and learning based on recent brain-based research, laying out an integrative approach to teaching and learning that promotes

\footnotetext{
*Corresponding author: mvandewa@wisc.edu
} 
inclusion, diversity, and social awareness, through embodied and contextualized learning. Ultimately, I will demonstrate that drama and performance are indispensable in teaching the whole child, whether taught as a discipline or a teaching tool.

\section{Results and discussion}

Using drama and performance techniques as educational tools to optimize learning is not a new concept $[1,2]$. Over the last century or so this non-product oriented way of working with theatre and performance techniques was identified as "drama".

Drama is process oriented - its focus is on the participants actively working within the art form, using the same instruments that actors use, Mind, Body, Heart, but to different ends. The benefits of drama as a teaching method are multiple: drama can reach students who are not reached through traditional methods, it engages students who are not engaged through traditional methods, it connects students to themselves and others, it transforms the traditional learning environment, and challenges students who are already considered successful under traditional paradigms. The last (20th) century saw some great developments in advocating for drama as a teaching tool and indeed it has spread all over the globe, but the anecdotal evidence was often not convincing enough to make a substantiated difference in formal schooling. This started to change at the end of the 1990s.

Research from other disciplines, most notably psychology, sociology, and the neurosciences, started to corroborate what drama practitioners have been saying for decades: human instincts call for embodied and contextualized learning.

Psychologist Howard Gardner stresses the importance of different ways of teaching and learning in Intelligence Reframed: Multiple Intelligences for the 21st Century [3]. Next, from a neurobiological perspective several scientist link emotion and the functioning of the brain in a series of highly successful studies [4-9]. Emotion, which is at the heart of drama is often ignored in education, while at the same time the negative effects of disturbed emotions on learning are well known. Daniel Goleman paved the way for a public understanding of the role of emotional intelligence (EQ) in his popular work Emotional Intelligence [10]. Finally, drama is doing and doing implies using your whole body. Affective neuroscientist and human development psychologist, Mary Helen ImmordinoYang has published research with compelling implications for embodied learning [11].

Another aspect that is crucial in our ever diversifying society is notions of consciousness and social awareness. Drama can help to recognize differences without value judgements.

One of the most interesting and fascinating aspects for a drama specialist regarding the research is that this legitimizes drama as in education, because it is based on scientific findings. Taken together, the research from the social sciences, educational psychology, and the neurosciences closely relate to the goals of drama as already articulated by Nellie McCaslin [12].

Since the early 1980s, eminent psychologist and scholar Howard Gardner has been advocating for the recognition of multiple intelligences, rather than focusing on the most commonly recognized verbal/linguistic and logical/mathematical aptitudes. While he claims that every human being possesses a basic set of intelligences in a particular blend unique to each person, he also points out that the destructive or constructive use of intelligences does not happen by accident [3, pp. 44-46]. As much as the decision on how to use intelligences is a question of value, it is also a matter of cultural circumstance and environment. Drama, because of its performative and interdisciplinary nature, can teach for multiple representations and understandings of important questions, topics, and themes [3]. This makes drama highly suitable to teach for inclusion, diversity, and social awareness [13-16]. 
A number of educational programs have been based on Multiple Intelligence theory [3].

Although the Mind-Body-Heart connection has been a subject of research and philosophy globally since the oldest times, and more in eastern than in the western philosophies, in our educational system the connection between emotion and reason in general is greatly ignored. Our educational system continues to favor "objective" IQ testing, erasing differences in background and cultural setting. As Gardner points out, there are three interconnected biases in our society: "westist, bestist, and testist" [17, p. 12; 3, pp. 14-18, pp. 135-139]. These notions are not limited to western industrial countries. We see the same phenomenon to various degrees in Russia, Japan, and China, among others.

However, these standardized test scores say little about students' quality of life, how they feel and engage with emotions, or how they work with others in their communities.

Psychologist Mihaly Csikszentmihalyi, one of the leading scholars of happiness and creativity, asserts that the ultimate pursuit and achievement of happiness depends very much on our personal perceptions and goals with a combination of cognitive and emotional processes happening in tandem with each other [18]. If we challenge ourselves with tasks that require a high degree of skill and commitment, we ultimately perceive ourselves as leading a more fulfilling life. The task needs to be challenging enough to evoke an "endorphin rush," but not so challenging it overwhelms.

Thus, if we see cognition and emotion as interrelated, then dramatic learning becomes essential: children learn about life through drama by exploring imaginary themes, topics, and issues on both emotional and cognitive levels simultaneously. Drama creates metaphors of our lives, which we lead through both cognitive and emotional domains; the two cannot and should not be separated.

Consider the following: "the present generation of children [is] more troubled emotionally than the last; more lonely and depressed, more angry and unruly, more nervous and prone to worry, more impulsive and aggressive" [10, p. 13].

This conclusion by Daniel Goleman more than 15 years ago, based on contemporary news reports and social science research, points out a deficiency in our educational and social system that cannot be remedied by traditional teaching and learning models. Goleman advocates attention for developing an emotional intelligence, the outcome of which "decent human beings — is more critical to our future than ever" [10, p. 263]. Research suggests that emotional health is fundamental to effective learning [10, pp. 7895]. But our collective emotional health has hardly increased since 1995 [19].

Drama techniques, such as role play, image work (tableaux), spotlight, hot seating, parallel play, etc. in teaching practices could be seen as a forum (or a means) to acquiring, experiencing, and enhancing emotional intelligence leading to children with confidence, curiosity, intentionality, self control, and the ability to relate, communicate, and cooperate [10, p. 194].

At the University of Wisconsin-Madison, the renowned neuropsychologist Richard Davidson has a whole research center studying the workings of the brain and emotional wellbeing in children and adults. Davidson argues [7] that different people have different emotional styles, and moreover, that the brain is not static and that these styles can shift and be modified, simply by brain exercises. Davidson's claims are all based in scientific research demonstrated in fMRI scans of people of all ages.

Key to Davidson's research are "mindfulness" exercises which can alter the brain patterns that make up your emotional style and can improve your resilience, outlook, social intuition, self awareness, sensitivity to context and attention, all areas that have according to Davidson "a solid foundation in the patterns of brain activity" (and note the connections of these areas with aforementioned MI and EQ).

Although drama is clearly a collaborative practice, drama methods connect to mindfulness in that it not only encourages participants to visualize possibilities in their 
minds, but also creates opportunities for individuals to embody these ideas, try on imagined transformations, and give life to various perspectives and ideas abstractly conceived in the brain. A connection with childhood play and drama, from the earliest ages on and ongoing, could potentially influence people's emotional style.

The role that art and creativity play in connections between the body, emotions, and the mind is perhaps most clearly laid out by scholar Mary-Helen Immordino-Yang, an affective neuroscientist and human development psychologist. In her groundbreaking work, Immordino-Yang studied the response of young adults to situations that elicit an emotional response, such as admiration, empathy, or sympathy. Immordino-Yang's research reveals a strong relationship between emotions, culture, and the brain. Immordino-Yang, much like Gardner and other scholars, suggests that thinking, feeling, and learning do not take place in separate vacuums, but instead, within social and cultural contexts: "[a] major part of how people make decisions has to do with their past social experience, reputation and cultural history" [11, p. 99].

We experience and make decisions in context, based on what we believe and how we identify. Our learning is embodied, our brain, emotions, and physiology are constantly connected. And we live in relationship to the rest of the world around us. A brain resides in a person, in a culture, in a world we are trying to understand [11]. Ultimately ImmordinoYang's research may provide one of the most convincing arguments for the necessity of creativity, including drama and performance. Her research suggests that drama, as part of collection of creative modes of expression, might be adopted not only as a tool for teaching and learning in education, but as a way to vicariously experience, practice, explore, play with real life situations in a fictional and safe environment. Human nature is to nurture and be nurtured - empathy is embodied.

\section{Conclusion}

Why is this research so important for the use of drama education? It is important to understand that all of the above is not new, rather, what is new is that the benefits and relevance of teaching drama in a formal or informal setting can now be scientifically demonstrated and that the impacts of this scientific research need to be further explored and embraced in conversations by educators, neuropsychologists, and theatre and drama specialists together, not in isolation. We, as educators, artists, scientists, and others, might reap great rewards by working together with open minds and willingness to step out of our comfort zones, particularly for making a case for using theatre and drama methods not only as a way to teach about art, but rather as a way we can improve our lives through the arts and education. Drama methods as an integrated way of teaching and an embodied form of learning aim for understanding and empathy [20, 21]. Drama methods offer invaluable resources that help us to imagine, create, debate, show, and understand what it means to be human.

\section{References}

1. J. Norris, Youth Theatre Journal, 30, 122-135 (2016). https://doi.org/10.1080/08929092.2016.1227189

2. C. O'Sullivan, N. Price, Drama Research: international journal of drama in education, 10(1), 1-41 (April 2019)

3. H. Gardner, Intelligence Reframed: Multiple Intelligences for the 21 st Century (Basic Books, New York, 1999) 
4. J. LeDoux, The Emotional Brain: The Mysterious Underpinnings of Emotional Life (Simon \& Schuster, New York, 1996)

5. A. Damasio, The Feeling of What Happens: Body and Emotion in the making of Consciousness (Harcourt Brace, New York, 1999)

6. A. Damasio, Looking for Spinoza: Joy, Sorrow, and the Feeling Brain (Harcourt Brace, New York, 2003)

7. R. Davidson, S. Begley, The Emotional Life of your Brain (Hudson, New York, 2012)

8. G. Pugh, The Emotional Brain, in Psychotherapy Meets Emotional Neuroscience, pp.47-61 (Routledge, London, 2019)

9. A. Waterhouse, The brain and emotions, in The Brain and Learning. Supporting Emotional Health and Wellbeing in School, pp. 179-238 (Routledge, London, 2020).

10. D. Goleman, Emotional Intelligence: Why It Can Matter More than IQ (Bantam, New York, 2005)

11. M.H. Immordino-Yang, Educational Philosophy and Theory, 43 (1), 98-103 (2011).

12. N. McCaslin, Creative Dramatics in the Classroom (Longman, New York, 1968)

13. H.M. Heikkinen, Journal of Social Science Education, 15(4), 32-39 (2016). https://doi.org/10.2390/jsse-v15-i4-1497

14. A. Galazka, Drama in Education for Sustainable Development, in INTED2017 Proceedings, 11th International Technology, Education and Development Conference, 6-8 March 2017, Valencia, Spain (2017). https://doi.org/10.21125/inted.2017.1643.

15. J. Dai, Studies in English Language Teaching, 8(2), 68-81 (2020). https://doi.org/10.22158/selt.v8n2p68

16. A. Lehtonen, E. Österlind, T. Viirret, International Journal of Education \& the Arts, 21(19), 1-27 (2020). https://doi.org/10.26209/ijea21n19

17. H. Gardner, Multiple Intelligences: The Theory in Practice (Basic Books, New York, 1993)

18. M. Csikszentmihalyi, Finding Flow: The Psychology of Engagement with Everyday Life (Basic Books, New York, 1997)

19. CDC Finds Rising Suicide Rates For Young People, NPR Morning Edition, Oct. 17, (2019). Accessed on: December 16, 2020. [Online]. Available:

https://www.npr.org/2019/10/17/770848694/cdc-finds-rising-suicide-rates-for-youngpeople

20. T. Papaioannou, A. Kondoyianni, Yaratıc Drama Dergisi, 14(2), 309-320 (2019). https://doi.org/10.21612/yader.2019.018

21. G. Mardas, K. Magos, RIELS Journal, 1(1), 74-85 (2020).

https://doi.org/10.47175/rielsj.v1i1.32 